\title{
A Survey on Business Management Tool in IT Sector for Digitizing Engineering Process Framework
}

\author{
T. Senthil Kumar \\ School of Computing Science and Engineering, \\ Vellore Institute of Technology, Vellore
}

\author{
J. Saira Banu \\ School of Computing Science and Engineering, \\ Vellore Institute of Technology, Vellore.
}

\begin{abstract}
Engineering process framework is a mechanism for abstracting the organizational processes and various elements such as infrastructure, business function, software processes and so on. It composed of process definitions, governance, dependencies and architecture related to process which synchronizes various elements. Process Framework is an important entity in the field of product based IT Industry. Each project is being carried out under the steps formulated by each process. So, it is necessary for an organization to have a process framework. Currently, most of the organizations are in the process of automating their own framework as it saves and generates lot of revenues to an organization. On the other side, they are also involved in tailoring the process framework manually which leads to miscommunication with the organization and customer. In this paper, we will explore the tools and technologies for automating the process framework and the issues to be considered for developing a Business management tool. Also, we illustrate the importance of tailoring perspective with the process framework tool for better communication between the organization and the customer which enables the cycle time reduction for thousands of projects executed within the organization.
\end{abstract}

\section{General Terms}

Process framework, Software, Tools.

\section{Keywords}

Governance, Dependencies, Tailoring, Business management, Business function

\section{INTRODUCTION}

Business management tools are used to help the managers to improve the performance of an organization, team and to achieve the business plan effectively. There are enormous business management tools available in the market. [8] In this paper, we mainly focus on the tools which are used for digitizing the process framework. Process framework is an important entity for an organization, since the customer orders for a particular product based on the quality of the process defined by the process owners. Current tailored processes are being manually updated by the process owner, which builds a huge gap between the organization and the customer. This gap can be merged with the help of a business management tool for critical situations. The following are the key features for an organization to go for a business management tool.[7] 1. The tool automatically codes for the framework, if the mapping is being done properly. 2 . The system has the feature of configuring the views for a system.3. The system has the feature of tailoring the project which is to be updated automatically with the process entries [5].
The distribution of the paper is as follows. Section 2 introduces the existing tools and technologies for business management tools. Section 3 presents a comparison study on existing business management systems, and their similarities. Section 4 provides the approaches to be considered for developing Business management tools. Section 5 illustrates the experimental results obtained from the above mentioned approaches. Finally, section 6 draws concluding remarks and draws directions for future work in this area.

\section{EXISTING TOOLS AND ITS FRAMEWORK}

In this section we discuss about the existing tools available in the market for digitizing the business process management.

\subsection{SharePoint}

SharePoint delivers a single frame for all corporate Web sites. It is a Microsoft product for dossier sharing and web publishing. It includes 1.Microsoft SharePoint Server, 2. Microsoft SharePoint Foundation, 3. Microsoft Search Server 4.Microsoft SharePoint Designer, 5.Microsoft SharePoint Workspace. Also it accelerates Built-in web content and document management capabilities to create, store, edit, and distribute web pages and store and distribute most office documents such as PDF, spreadsheets, and text documents. Workflow tools helps in systematizing business processes such as approvals and publishing. Web Application is the underlying framework of the SharePoint Site. It's a collection of ASP scripts and HTML. Site Collection can be considered as a box which contains many individual sites. Central Administration allows us to manage Web application, Site Collection and Individual Sites. Database (Either a dedicated SQL Server or Internal Windows Database) stores all the data related to web applications. Each web application will have a separate database.

\subsection{Eclipse Process Framework (EPF)}

EPF proposal was first posted on the eclipse website in the year 2005 - 2006. Projects have been created by mid 2006 and EPF v1.5 was released during mid 2007 which include APUs, SPEM 2.0, Scrum process, Basic unified process. Eclipse Process Framework is an open source project managed by the Eclipse foundation which aims at producing a customized software process engineering scaffold, with emblematic process content and tools, sustaining a broad variety of augmented platforms and applications. UMA stands for "Unified Method Architecture". It describes the metamodel for the EPF method content and defines the processes. It provides archetypal tools for software process engineering 1.Method content and process authoring 2.library management 3 . Configure and 4. Publishing a process. 
Method content entails reusable information such as roles, tasks, work products and relationships between them. Guidance is associated with Templates, Checklists and guidelines which provides the detailed information about the corresponding method content associated with the appropriate business processes .Related elements are being grouped together by a functionality called categories which is of two types: Standard category and custom category. There are five standard types: disciplines, domains, work product kinds, role sets and tools. Custom Processes create end-to-end processes (called delivery processes) or reusable process components (called capability patterns).Capability patterns describe the series of related tasks, performed to achieve a better purpose. The Browsing perspective is proposed for a process engineer and project manager to browse the content in HTML format. Publishing component provides configuration or process to a static website. It transforms the generic XML file into a XHTML web page. Hyper-links are generated by utilizing the relationships established during the method content and process authoring. Tree browsers are provided based on the configuration view and user-defined categorization of the content [4].

\subsection{Rational Method Composer}

The Rational Method Composer software is a out-and-out business-driven development that align development, processes and line-of business teams. It enriches the capability to wrestle key initiatives and significances i.e., SOA, compliance, packaged application development. It improves team effectiveness, candidness, and yield which increases the quality of the project. Built on top of the Eclipse framework, the Rational Method Composer software adds new best practices to the RUP methodology that leverage IBM's expertise in portfolio management, collaborative distributed development and Service Oriented Architectures (SOAs). It replaces the Rational Process Workbench offering with new, open source process customization tools that will tightly link Business and IT activities, collaborate process more effectively, reduces failures in software project, and save time and money [2].

\subsection{IRIS Process Author}

IRIS Process Author uses a visual process management system that provides collaborative authoring and tailoring of process assets in a concrete way that ensures an organization is able to meet its governance objectives. Processes are managed within well-structured process architecture to facilitate efficient customization and reuse of process assets across the organization. IRIS Process Author methodology allows organizations to merge the best industry content with their own established practices to launch a rich set of assets that can be simply deployed in the organization without any problem. It visually Create and Tailor Processes, develop a Robust Process Architecture to Manage the Process Assets, Publish, Distribute and Enact Tailored Processes.

\subsection{TIBCO}

TIBCO Business Studio is a standards-based, unified Business Process Modeling (BPM) and development environment that permits professional experts and IT to team up to model, develop, and install business process claims. Business specialists can model business processes, user interface forms and page flows, business objects (data), and organizational structures. Simulation of Process models is done to understand their behavior and impact it made on the business.
Process developers also use TIBCO Business Studio to expand the process applications and fix them to TIBCO Active Matrix BPM or TIBCO Silver BPM. The model-driven approach in implementing business process applications simplifies process modeling and development because it requires virtually no coding. It allows business experts and process developers to develop process applications which meet business requirements by means of a fast, iterative, and collaborative approach.

\subsection{Intalio}

Intalio delivers an alternative for business process modeling (BPM) tools. The product provides clear and well established user interface and low price for modeller part of the tools. The modeller is evaluated against a method constructed in this study. The evaluation method entails visual elements and capabilities of the modeller against the Business Process Modeling Notation (BPMN) -standard and constructing a process model with the tool. The usability of the tool is evaluated and the resulting Business Process Executable Language (BPEL) is compared against latest draft of WSPBEL 2.0. The modeller is usable, and supports BPMN elements well enough to be used for everyday modeling. There are certain stability issues with the deployment of this tool.

\subsection{Lombardi}

Web Sphere Lombardi Edition offers a unified business process management (BPM) .It is designed to make it easy for process holders and business users, and IT to work together and participate openly in enlightening their processes. It manages the processes directly from Microsoft Outlook or Microsoft Sharepoint. It also provides Graphical workspace for rapid composition, collaboration and continuous change designed to build it easy for all process stakeholders. It also suited to implement business processes exhibiting a high degree of end user involvement and frequent change.

\section{DIFFERENCES AND SIMILARITIES OF EXISTING TOOLS}

Table 1: Differences and Similarities

\begin{tabular}{|c|c|c|c|}
\hline Product & Vendors & $\begin{array}{c}\text { Current } \\
\text { versions }\end{array}$ & Model \\
\hline SharePoint & Microsoft & $\begin{array}{c}\text { SharePoint } \\
2010\end{array}$ & $\begin{array}{c}\text { Business Process } \\
\text { modeling } \\
\text { Workflow }\end{array}$ \\
\hline IRIS & Osellus & IRIS 2.0 & Spem based \\
\hline $\begin{array}{c}\text { Eclipse } \\
\text { Process } \\
\text { composer }\end{array}$ & Eclipse & EPF 1.5.1.1 & UMA \\
\hline $\begin{array}{c}\text { Rational } \\
\text { Method } \\
\text { Composer }\end{array}$ & IBM & RMC v7.5.1 & UMA \\
\hline TIBCO & TIBCO & TIBCO & Business Process \\
\hline
\end{tabular}




\begin{tabular}{|c|c|c|c|}
\hline $\begin{array}{c}\text { Business } \\
\text { studio }\end{array}$ & $\begin{array}{c}\text { Business } \\
\text { studio 3.0 }\end{array}$ & $\begin{array}{c}\text { Modeling(Eclipse } \\
\text { based) }\end{array}$ \\
\hline $\begin{array}{c}\text { Windows } \\
\text { Workflow } \\
\text { foundation }\end{array}$ & Microsoft & WF4 & $\begin{array}{c}\text { Business process } \\
\text { modeling } \\
\text { workflow }\end{array}$ \\
\hline $\begin{array}{c}\text { Intalio } \\
\text { BPMS }\end{array}$ & Intalio & $\begin{array}{c}\text { Intalio } \\
\text { BPMS 6.0.3 }\end{array}$ & BPMN 2.0 \\
\hline Lombardi & IBM & $\begin{array}{c}\text { Websphere } \\
\text { Lombardi } \\
\text { edition 7.2 }\end{array}$ & $\begin{array}{c}\text { Business Process } \\
\text { Modeling }\end{array}$ \\
\hline
\end{tabular}

\begin{tabular}{|c|c|c|c|}
\hline $\begin{array}{c}\text { Windows } \\
\text { Workflow } \\
\text { foundation }\end{array}$ & $\begin{array}{c}\text { process } \\
\text { framework }\end{array}$ & $\begin{array}{c}\text { Authoring } \\
\text { and } \\
\text { managing } \\
\text { workflow }\end{array}$ & $\mathrm{n} / \mathrm{a}$ \\
\hline Intalio & $\begin{array}{c}\text { BPEL,Eclipse } \\
\text { SOA Tools } \\
\text { PPMS }\end{array}$ & $\begin{array}{c}\text { Facilitates } \\
\text { collaboration } \\
\text { of business } \\
\text { processes }\end{array}$ & $\mathrm{n} / \mathrm{a}$ \\
\hline Lombardi & J2EE, SOA & $\begin{array}{c}\text { Collaborate, } \\
\text { manage and } \\
\text { improve } \\
\text { process } \\
\text { performance }\end{array}$ & \\
\hline & & $\mathrm{n} / \mathrm{a}$ \\
\hline
\end{tabular}

\begin{tabular}{|c|c|c|c|}
\hline Product & $\begin{array}{c}\text { Development } \\
\text { Technology }\end{array}$ & Tool usage & $\begin{array}{c}\text { Tailoring } \\
\text { Perspective }\end{array}$ \\
\hline SharePoint & $\begin{array}{c}\text {.NET } \\
\text { framework }\end{array}$ & $\begin{array}{c}\text { Content } \\
\text { management, } \\
\text { File sharing, } \\
\text { web } \\
\text { publishing }\end{array}$ & $\mathrm{n} / \mathrm{a}$ \\
\hline IRIS & .NET,J2EE & $\begin{array}{c}\text { Collaborative } \\
\text { process } \\
\text { authoring }\end{array}$ & $\begin{array}{c}\text { Publish, } \\
\text { distribute and } \\
\text { enact } \\
\text { processes. } \\
\text { Tailor } \\
\text { Methodologies } \\
\text { based on user } \\
\text { choice }\end{array}$ \\
\hline $\begin{array}{c}\text { Eclipse } \\
\text { Process } \\
\text { Framework } \\
\text { composer }\end{array}$ & Java & $\begin{array}{c}\text { Process } \\
\text { authoring, } \\
\text { configure } \\
\text { and } \\
\text { publishing } \\
\text { the process }\end{array}$ & $\mathrm{n} / \mathrm{a}$ \\
\hline $\begin{array}{l}\text { Rational } \\
\text { Method } \\
\text { Composer }\end{array}$ & .NET,J2EE,SOA & $\begin{array}{c}\text { Authoring, } \\
\text { Tailoring, } \\
\text { view, } \\
\text { configure } \\
\text { and publish } \\
\text { as website }\end{array}$ & $\begin{array}{c}\text { Process } \\
\text { content, out- } \\
\text { of-box } \\
\text { delivery } \\
\text { process and } \\
\text { pre-defined } \\
\text { processes }\end{array}$ \\
\hline $\begin{array}{l}\text { TIBCO } \\
\text { Business } \\
\text { studio }\end{array}$ & SOA,J2EE & $\begin{array}{c}\text { Collaborate, } \\
\text { develop and } \\
\text { deploy } \\
\text { business }\end{array}$ & $\mathrm{n} / \mathrm{a}$ \\
\hline
\end{tabular}

\section{ISSUES TO BE CONSIDERED IN DEVELOPING BUSINESS MANAGEMENT TOOL}

\subsection{Understanding the importance of business processes}

Companies must capture business processes such that others can understand how they work, the person involved, and how activities start from starting to end. Typically a business analyst models these processes. Many businesses desire to develop their business processes to decrease inefficiencies, drive down costs, and respond faster to customer requests. A process must be captured first before redesigning it. Redesign can be done after the process has been properly documented. Typically a technical analyst, or perhaps who understands both the business needs, and the IT systems models. The best way to improve the efficiency of a business process is to apply automation to it and to reduce the manual work. The process can be performed faster and at a reduced cost.

\subsection{Modeling}

Modeling a process is very important as it determines the outcome of the particular product. A software life cycle model gives the descriptive or prescriptive characterization of software development process. A descriptive model explains the history of particular software system development process. Descriptive models may be used as the basis for improving software development processes; a prescriptive model prescribes how a new software system should be developed. Prescriptive models are used as rule or frameworks to arrange and structure software development activities. There is several software development approaches have been used since the origin of information technology. These are: Waterfall (a linear framework), Prototyping (an iterative framework) Incremental (a combined linear-iterative framework) Spiral (a combined linear-iterative framework), Rapid application development (an iterative framework) [3]. 


\subsection{Tailoring Issue}

Every software project is unique and hence requires a unique software process. However, as the differences in the long run are fewer than the similarities, it would not be efficient to start the process design from scratch every time a new project is planned. Therefore, it is common to start with a readymade process framework and then tailor it to fit the needs of a particular project. A process framework is a set of ready-made production-ready process models and software methods that have been designed to fit well with each other. During tailoring, only the parts of the framework that are relevant to the project in question are selected and combined into a process instance that is to be followed throughout the project a good example of a process framework is the Rational Unified Process9 by IBM.

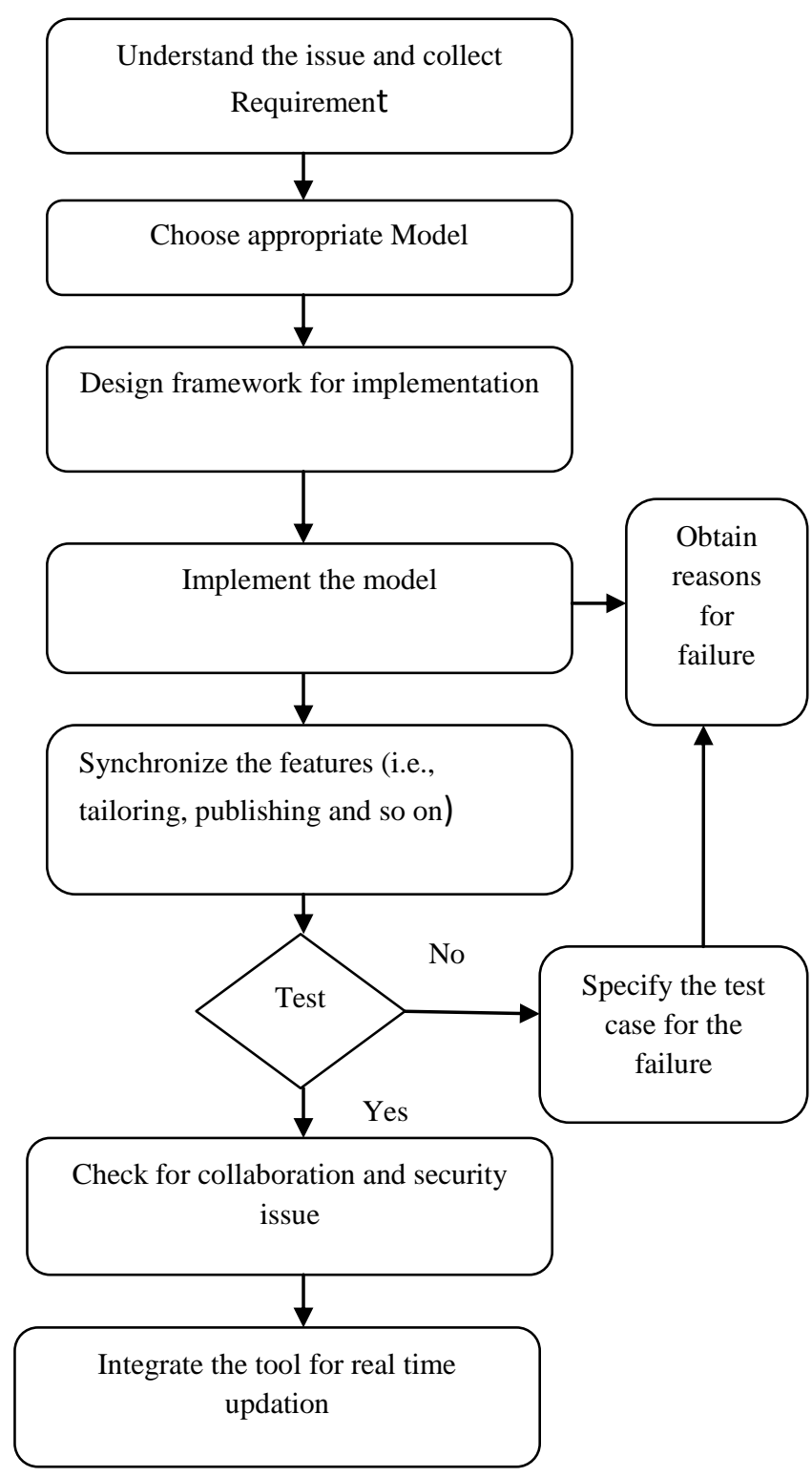

Figure 1: Flow Diagram for Developing Business Management Tool

\subsection{Synchronization Issues}

In large companies there may be several projects going on in parallel that are based on the same core process and contribute new information to the process repository simultaneously. Consequently, the version control system must be able to manage tracing, branching and merging of different versions of both the core process and the project-specific tailored processes. It is impossible for two users to work on the same process library simultaneously, causing a possible block to collaboration. This problem can be worked around by making sure the libraries are small enough, which is a good idea in any case as it also makes reuse easier as well.

\subsection{Integration Issues}

Except for very small projects, there are several tools and systems that need to access the information in the process repository. The developers needs a browse able view of the process, the customers requires a printed copy for documentation purposes, the project manager requires scheduling and resource information for the project management tool, the webmaster requires some information for the corporate intranet, the quality management team wants to extract the information for the audit checklist, the customer wants a description of the process for the project documentation. Many tools are only able to export to HTML, XML and sometimes Microsoft Word or PDF. However, to fully integrate with other tools it is important that a process authoring tool supports advanced user-definable queries and exports. Preferably, it should be possible to define advanced imports as well in order to aid data synchronization. Information that cannot be properly accessed is almost as bad as having no information at all [1]

\subsection{Collaboration issue}

Many tools are still designed around the traditional process engineering principle, where the processes are designed by a dedicated process engineering team and then exported to the software engineering teams for adoption. It is a singledirectional form of communication, where the process engineers tell the software engineers, who presumably are experts at what they do, how they should do their work. That the process repository should not only contain process models and method descriptions, but also best practices and previous experiences etc. This knowledge is not held by the process engineers but by the software engineers, who utilize the process in real-world projects

In a company, tools should be evaluated before implementing the process framework. The purpose of this evaluation is based on the requirements obtained from the customer and to test how well the tools performed in typical real-world usage scenarios.[4] These scenarios deal with process authoring, tailoring, collaboration, and integration with project management tools

The formula for evaluating tools is as follows

Total value $=\left(\mathrm{R}_{1} * \mathrm{~F}_{1}\right)+\left(\mathrm{R}_{2} * \mathrm{~F}_{2}\right)+\ldots . .+\left(\mathrm{R}_{\mathrm{n}} * \mathrm{~F}_{\mathrm{n}}\right)$

$\mathrm{R}=$ input importance rating

$\mathrm{F}=$ tool rating for the particular input

$\mathrm{N}=$ number of inputs for the particular tool

For example, consider company A evaluates tool with following requirement as given below. 
Table 2: Scale values

\begin{tabular}{|l|l|}
\hline $\begin{array}{l}\text { Functional Products } \\
\text { Requirements Importance } \\
\text { Rating scale }\end{array}$ & Relationships \\
\hline $9=$ Critical & $1=$ Low \\
$7=$ Very Important & $3=$ Weak \\
$5=$ Important & $5=$ Medium \\
$3=$ Useful & $7=$ Strong \\
$1=$ Somewhat useful & $9=$ Very Strong \\
\hline
\end{tabular}

Table 3: Evaluation of tools

\begin{tabular}{|c|c|c|c|c|c|c|c|c|c|}
\hline $\begin{array}{l}\mathbf{S} \\
\mathbf{N} \\
\mathbf{0}\end{array}$ & Requirements & $\begin{array}{l}\text { Im } \\
\text { po } \\
\text { rta } \\
\text { nc } \\
\text { e } \\
\text { Ra } \\
\text { tin } \\
\text { g }\end{array}$ & $\begin{array}{l}\text { Sh } \\
\text { ar } \\
\text { e } \\
\text { Po } \\
\text { int }\end{array}$ & $\begin{array}{l}\mathbf{I} \\
\mathbf{R} \\
\mathbf{I} \\
\mathbf{S}\end{array}$ & $\begin{array}{l}\mathbf{E} \\
\mathbf{P} \\
\mathbf{F} \\
\mathbf{C}\end{array}$ & $\begin{array}{l}\mathbf{R} \\
\mathbf{M} \\
\mathbf{C}\end{array}$ & $\begin{array}{l}\mathbf{W} \\
\mathbf{F}\end{array}$ & $\begin{array}{l}\text { In } \\
\text { ta } \\
\text { lio }\end{array}$ & $\begin{array}{l}\text { Lom } \\
\text { bard } \\
\text { i }\end{array}$ \\
\hline 1 & $\begin{array}{l}\text { Ease to author, } \\
\text { maintain } \\
\text { process }\end{array}$ & 9 & 3 & 9 & 9 & 9 & 1 & 9 & 7 \\
\hline 2 & $\begin{array}{l}\text { Interface for } \\
\text { process } \\
\text { elements based } \\
\text { on project } \\
\text { configuration }\end{array}$ & 9 & 7 & 7 & 9 & 9 & 3 & 7 & 7 \\
\hline 3 & $\begin{array}{l}\text { Search } \\
\text { capability }\end{array}$ & 5 & 7 & 3 & 5 & 7 & 7 & 3 & 3 \\
\hline 4 & $\begin{array}{l}\text { Process } \\
\text { artifacts }\end{array}$ & 9 & 7 & 5 & 9 & 9 & 5 & 5 & 1 \\
\hline 5 & $\begin{array}{l}\text { Integration with } \\
\text { clearcase, CVS }\end{array}$ & 9 & 8 & $\begin{array}{l}\mathrm{n} \\
/ \\
\mathrm{a}\end{array}$ & 5 & 9 & 1 & 3 & 7 \\
\hline 6 & $\begin{array}{l}\text { User defined } \\
\text { views }\end{array}$ & 9 & 7 & 4 & 9 & 9 & 1 & 7 & 5 \\
\hline 7 & $\begin{array}{l}\text { Import other } \\
\text { plug-ins }\end{array}$ & 3 & 1 & 1 & 3 & 9 & 5 & 7 & 5 \\
\hline 8 & $\begin{array}{l}\text { Query based } \\
\text { category }\end{array}$ & 5 & 1 & 1 & 1 & 7 & 1 & 5 & 5 \\
\hline 9 & $\begin{array}{l}\text { Filter content } \\
\text { on attributes }\end{array}$ & 7 & 7 & 3 & 3 & 9 & 1 & 7 & 7 \\
\hline \multicolumn{3}{|c|}{ Relative Importance } & $\begin{array}{l}38 \\
0\end{array}$ & $\begin{array}{l}2 \\
8 \\
1\end{array}$ & $\begin{array}{l}4 \\
2 \\
9\end{array}$ & $\begin{array}{l}5 \\
6 \\
5\end{array}$ & $\begin{array}{l}1 \\
6 \\
1\end{array}$ & $\begin{array}{l}38 \\
9\end{array}$ & 347 \\
\hline
\end{tabular}

Now, Company A evaluates the values in the table and tool which gives the largest value is the recommended tool for starting the project i.e., Company A will go for Rational Method Composer for process management. Consider the following graph which illustrates the evaluation procedure.

In this Graph $\mathrm{X}$ axis represents the product, $\mathrm{Y}$ axis represents the rating obtained from functional requirement of the product and importance and colored box represents the requirements obtained from Table 3. From this graph the user can identify how much the particular tool is used for user's requirement.

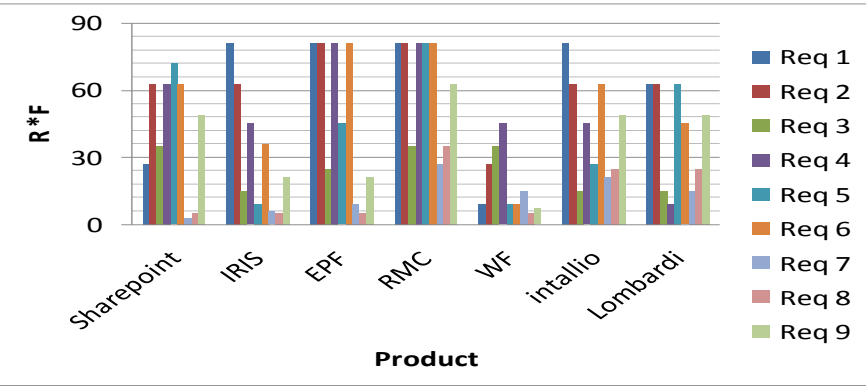

Figure 2: Tool usage for user requirement

\section{REFERENCES}

[1] Joshi N, Riley W, Schneider J, Tan Y, 2007 "Integration of domain-specific IT processes and tools in IBM Service Management". IBM Systems Journal, Volume $46: 497-511$

[2] Robert N. Charette, September 2005 "Why Software FAILS”. IEEE Spectrum, 42(9):42-49

[3] Scott W. Ambler, June 2008 "Has Agile Peaked? Dr. Dobb's Journal: The World of Software Development", 33(6):52-54

[4] V. Nikulsins and O. Nikiforova, 2010"Tool Integration to Support SPEM Transformations in Eclipse", Scientific J. Riga Tech. Univ., vol. 45:60-67; https://ortus.rtu.lv/science/en/publications/8640/fulltext

[5] Xuan-Linh Tran, Huynh T V, Shoval S, Ferris T,2008 "Tool selection process and its management for small and medium enterprises in defense projects", IEEE International Conference on System of Systems Engineering:1-7.

[6] Yasha Wang, Dongni Li, Xiaoyang He, 2005 "A process management tool supporting component-based process development and hierarchical management mechanism. “ The Fifth International Conference on Computer and Information Technology: 906-910.

[7] Tomi Mustonen, Matti Karvonen, Liisa Soininen, Kirsi Hellsten,Tuomo Kässi, "Digitizing Business Processes in the Intersection of Energy, Forest and ICT Industries", Research report, 2008.

[8] Neelamkavil, J,"A Review of Existing Tools and their Applicability to Facility Maintenance Management", Research report, 2009. 